\title{
PENGARUH SUPERVISI KEPALA SEKOLAH DAN IKLIM KERJA TERHADAP MOTIVASI KERJA GURU SEKOLAH DASAR DI KECAMATAN KERTASEMAYA KABUPATEN INDRAMAYU
}

\author{
Ayi Meldarena \\ SDN 2 Kliwed Kertasmaya, Indramayu, Jawa Barat-Indonesia, ayimeldarena@yahoo.co.id
}

Received November 24, 2018, reviewed 30 Januari, 2019, published Maret 30, 2019

Citation: Meldarena, A. (2019). Pengaruh Supervisi Kepala Sekolah dan Iklim Kerja Terhadap Motivasi Kerja Guru Sekolah Dasar di Kecamatan Kertasemaya Kabupaten Indramayu. Edum Journal, Vol 2, No 1, Hal 1-14, Maret 2019.

DOI:

\begin{abstract}
ABSTRAK
Tujuan dalam penelitian ini untuk mengetahui seberapa besar pengaruh supervisi kepala sekolah dan iklim kerja secara simultan terhadap motivasi kerja guru SD di Kecamatan Kertasemaya Kabupaten Indramayu. Metode penelitian yang digunakan yakni metode survey dengan teknik korelasional dan regresi dan data teknik pengumpulan yang digunakan yakni data angket skala Likert terhadap 65 orang guru SD negeri di kecamatan Kertasemaya Kabupaten Indramayu. Hasil penelitian dapat disimpulkan bahwa: (1) Terdapat pengaruh yang signifikan supervisi kepala sekolah terhadap motivasi kerja guru SD di kecamatan Kertasemaya Kabupaten Indramayu. Besarnya pengaruh supervisi kepala sekolah terhadap motivasi kerja guru adalah sebesar $17,3 \%$, sementara sisanya dipengaruhi oleh variabel lain. (2) Terdapat pengaruh yang signifikan iklim kerja terhadap motivasi kerja guru SD di Kecamatan Kertasemaya Kabupaten Indramayu. Besarnya pengaruh iklim kerja terhadap motivasi kerja guru adalah sebesar $21 \%$, sementara sisanya dipengaruhi oleh variabel lain selain supervisi kepala sekolah, yang tidak dikaji dalam penelitian ini (Epsilon). (3) terdapat pengaruh yang signifikan secara simultan supervisi kepala sekolah dan iklim kerja terhadap motivasi kerja guru SD di Kecamatan Kertasemaya Kabupten Indramayu. Besarnya pengaruh supervisi kepala sekolah dan iklim kerja secara simultan terhadap motivasi kerja guru SD di Kecamatan Kertasemaya Kabupaten Indramayu adalah sebesar 32\%, sementara sisanya dipengaruhi oleh variabel lain, yang tidak dikaji dalam penelitian ini (epsilon). Untuk meningkatkan motivasi kerja perlu dilakukan supervisi kepala sekolah secara rutin dan perlu adanya iklim kerja yang kondusif.
\end{abstract}

Kata Kunci: Supervisi Kepala Sekolah, Iklim Kerja, Motivasi Kerja Guru

\begin{abstract}
The purpose of this study was to find out how much influence the principal's supervision and work climate simultaneously had on the motivation of elementary school teachers working in Kertasemaya Subdistrict, Indramayu Regency. The research method used is the survey method with correlational techniques and regression and the collection technique data used are Likert scale questionnaire data on 65 public elementary school teachers in the Kertasemaya sub-district of Indramayu Regency. The results of the study can be concluded that: (1) There is a significant effect of supervision of the principal on the motivation of elementary school teachers working in the sub-district of Kertasemaya, Indramayu Regency. The magnitude of the influence of the principal's supervision of teacher work motivation is $17.3 \%$, while the rest is influenced by other variables. (2) There is a significant effect of work climate on the motivation of elementary school teachers working in Kertasemaya Subdistrict, Indramayu Regency. The magnitude of the influence of the work climate on teacher work motivation is $21 \%$, while the rest is influenced by other variables besides the supervision of the principal, which are not examined in this study (Epsilon). (3) there is a simultaneous significant effect of school principal supervision and work climate on the motivation of elementary school teachers working in Kertasemaya District, Indramayu Regency. The magnitude of the influence of the principal's supervision and the work climate simultaneously on the motivation of elementary school teachers working in Kertasemaya Subdistrict, Indramayu Regency is 32\%, while the rest is influenced by other variables, which are not examined in this study (epsilon). To increase work motivation, it is necessary to supervise the principal regularly and need a conducive work climate.
\end{abstract}


Keywords: Principal Supervision, Work Climate, Motivation of Teacher Work

PENDAHULUAN

Pembelajaran merupakan inti dari peningkatan mutu pendidikan di sekolah. Pembelajaran yang bermakna akan membantu siswa mengembangkan kreatifitas, dan itu semua dapat berhasil jika proses pembelajaran yang dilaksanakan guru terencana dan terealisasi dengan baik (Kenedi, 2017). Guru harus berinteraksi dengan siswa, mendorong interaksi antar siswa satu dan siswa lainnya, memotivasi siswa mengeluarkan pendapatnya, berdiskusi bersama untuk dapat mencari informasi yang diperlukan (Manizar, 2015).

Salah satu yang mempengaruhi tinggi rendahnya kinerja guru yakni tinggi rendahnya motivasi guru. Faktor-faktor yang mempengaruhi kinerja guru diantaranya tingkat pendidikan guru, supervisi pengajaran, program penataran, iklim yang kondusif, sarana dan prasarana, kondisi fisik dan mental guru, gaya kepemimpinan kepala sekolah, jaminan kesejahteraan, kemampuan manajerial kepala sekolah dan lain-lain (Faizin, 2018).

Rendahnya motivasi kerja guru dalam pelaksanaan pembelajaran juga disampaikan oleh Kepala Seksi Kurikulum Dinas Pendidikan Kabupaten Indramayu. Berdasarkan hasil survey sebuah lembaga independen tahun 2013 dengan skala nasional bahwa PTK (Pendidik dan Tenaga Kependidikan) sebanyak $46 \%$ kinerjanya belum maksimal. Dari 54\% sisanya ternyata terlambat datang ke sekolah sebanyak $31,70 \%$ yang datang mengajar ke kelas tidak membuat RPP atau media pembelajaran sebanyak 47,2 \% guru tidak langsung masuk kelas sebanyak $23 \%$ dan datang ke sekolah tidak langsung mengajar sebanyak $15 \%$. Dari deskripsi di atas, maka terdapat realita yang berhubungan dengan kesiapan proses pembelajaran yang akan dilaksanakan oleh guru.

Hasil Uji Kompetensi Guru (UKG) tahun 2015 secara nasional sebagai berikut : 


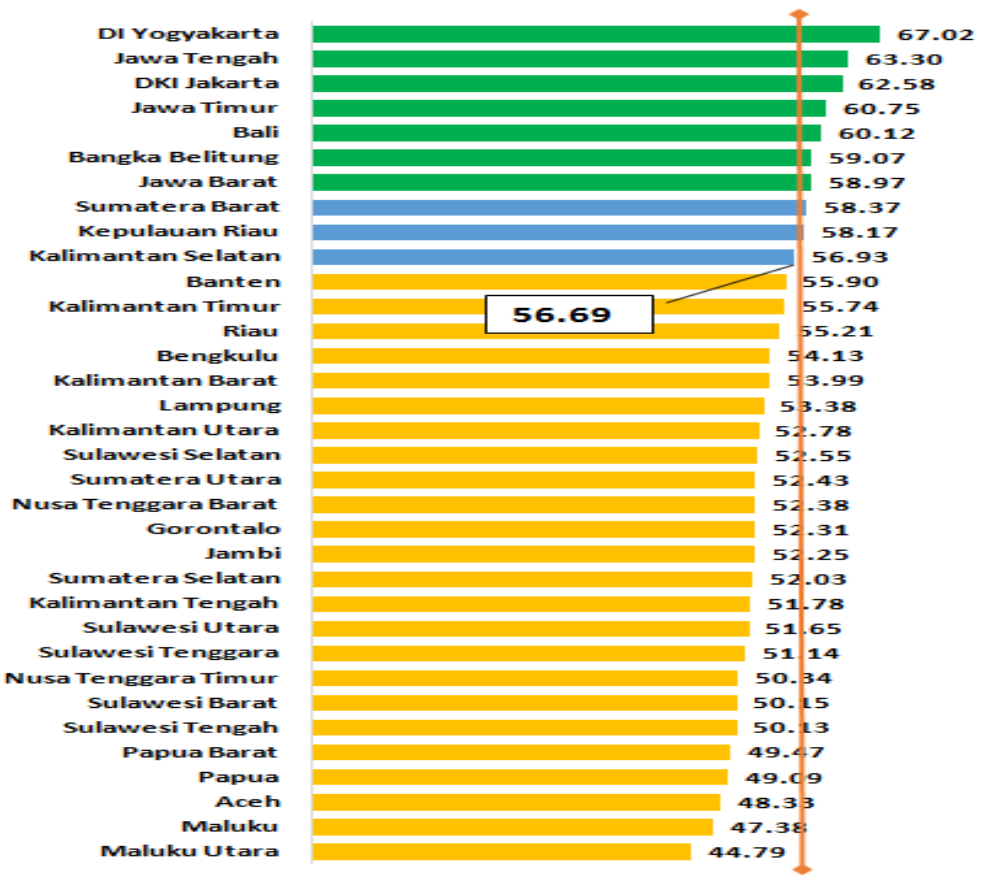

Sumber: Kemendikbud (2016)

Berdasarkan hasil UKG tahun 2015, sehingga dapat menumbuhkan kreatifitas Jawa Barat berada pada peringkat ke tujuh siswa yang pada akhirnya akan dan Kabupaten Indramayu berada pada meningkatkan mutu pendidikan secara peringkat ke 26 dari 27 kabupaten/kota di keseluruhan (Jumadiah, dkk, 2016).

Jawa barat. Beranjak dari hasil UKG inilah Usaha pencapaian tujuan belajar juga ada banyak kemungkinan yang perlu diciptakan adanya sistem lingkungan mengisyaratkan kemampuan atau atau kondisi belajar yang kondusif (Harjali, kompetensi guru di kabupaten Indramayu 2016). Lingkungan atau iklim kerja yang terindikasi rendah. Salah satu kondusif diantaranya ada keharmonisan kemungkinannya motivasi kerja guru rendah antara kepala sekolah dengan guru atau guru sehingga berimbas terhadap hasil UKG yang dengan guru lainnya. Suasana sekolah juga menilai kompetensi pedagogik dan berpengaruh terhadap kenyamanan profesional guru

Supervisi ini dilaksanakan bukan untuk mencari kesalahan dalam proses belajar mengajar yang dilakukan guru tetapi bertujuan untuk membimbing, mencari solusi dari setiap permasalahan PBM agar pembelajaran, ruangan yang panas atau suara bisingnya kendaraan menjadi salah satu keluh kesah guru (Sutarsanah, 2011).

Masalah motivasi guru untuk melaksanakan tugas dan fungsi sebagai guru menjadi salah satu masalah yang ada di tercipta pembelajaran yang bermakna dunia pendidikan kita khususnya di 
lingkungan UPTD Pendidikan Kecamatan

Kertasemaya Kabupaten Indramayu.

Motivasi dapat ditumbuhkan dengan berbagai cara. Kepala sekolah sebagai leader di sekolah mestinya juga sebagai motivator yang dapat menumbuhkan motivasi kerja guru di lingkungan tempat tugasnya. Lingkungan fisik tempat tugas terkadang sangat memungkinkan guru tidak memiliki motivasi kerja yang maksimal. Suasana kerja yang harmonis dapat pula

menumbuhkan motivasi kerja guru yang mulai redup (Supriyo, 2015).

Banyak faktor yang mempengaruhi motivasi guru dalam melaksanakan kinerjanya. Penulis mencoba mengidentifikasi faktor-faktor penyebabnya, diantaranya kepemimpinan kepala sekolah, sarana prasarana, profesionalisme guru, kegiatan supervisi kepala sekolah, iklim kerja, lingkungan kerja, mutu sekolah, persaingan berprestasi, dan masih banyak lagi.

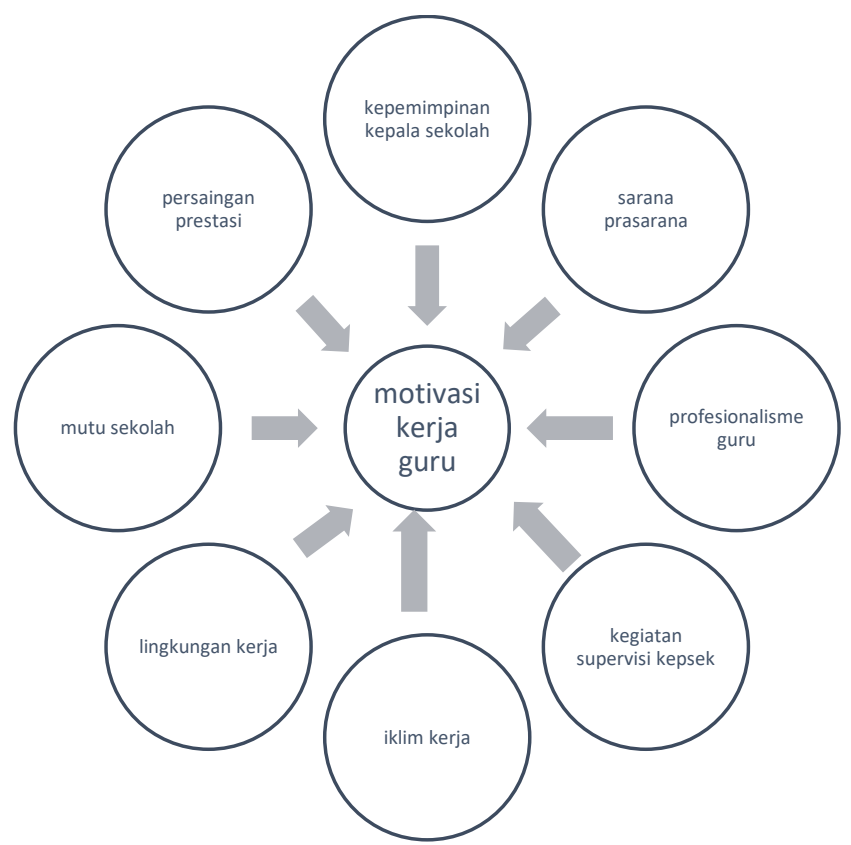

Diagram 1. Faktor motivasi kerja guru

Dari sekian banyak faktor yang Kertasemaya Kabupaten Indramayu yang mempengaruhi motivasi guru, maka menyebutkan sekolah dasar di wilayah pengaruh kegiatan supervisi kepala sekolah UPTD Pendidikan Kecamatan Kertasemaya dan iklim kerja saja yang menjadi fokus hanya melaksanakan kegiatan supervisi oleh penelitian yang penulis laksanakan. kepala sekolah satu kali dalam setahun.

Pemilihan faktor itu didasari atas data yang Berdasarkan latar belakang di atas, didapat dari UPTD Pendidikan Kecamatan maka penulis menyatakan bahwa motivasi 
kerja guru SD di Kecamatan Kertasemaya

Kabupaten Indramayu belum sesuai harapan yang diduga disebabkan oleh kurangnya supervisi yang dilaksanakan kepala sekolah dan kurang mendukungnya iklim kerja.

\section{METODE PENELITIAN}

Metode yang dipakai dalam penelitian ini adalah metode survey dengan teknik korelasional dan regresi. Kerlinger yang dikutip oleh Akdon \& Hadi (2005:91) bahwa penelitian survey merupakan penelitian yang dilakukan pada populasi besar maupun kecil, tetapi data yang dipelajari adalah data dari sampel yang diambil dari populasi tersebut, sehingga ditemukan kejadian - kejadian relatif, distribusi, dan hubungan antar variabel sosiologis maupun psikologis.

Penelitian ini dilaksanakan untuk mencari analisis hubungan antara supervisi kepala sekolah dan iklim kerja dengan motivasi kerja guru SD di Kecamatan Kertasemaya Kabupaten Indramayu dengan teknik korelasional dan regresi. Adapun jenis penelitian yang digunakan adalah kuantitatif, yaitu penelitian berdasarkan pada perhitungan angka - angka atau statistik dari suatu variabel untuk dapat dikaji secara terpisah - pisah kemudian dihubungkan.

Populasi dalam penelitian ini adalah semua guru PNS SD Negeri yang berada di lingkungan UPTD Pendidikan Kecamatan Kertasemaya yang memiliki karakteristik sebagai berikut: 1). Memiliki homogenitas profesi yaitu profesi guru, 2). Pengalaman sebagai guru tidak sama, 3). Guru SD di Kecamatan Kertasemaya tidak sama frekwensi mengikuti diklat, penataran, seminar atau workshop, 4). Bertugas di sekolah negeri yang berbeda situasi dan kondisinya, 5). Memiliki latar belakang pendidikan yang beragam. Diketahui jumlah populasi guru SD di Kecamatan Kertasemaya Kabupaten Kertasemaya N = 186 orang dan tingkat presisi yang ditetapkan adalah $10 \% .65$ guru.

Teknik pengumpulan yang digunakan dalam penelitian ini yakni (1) angket; (2) pedoman wawancara; (3) pengamatan. Setelah semua data yang diperlukan terkumpul, selanjutnya dilakukan langkahlangkah analisa data dan pengujian Hipotesis melalui pendekatan olahan data statistik SPSS versi 20 for windows. Data ditampilkan dalam bentuk tabulasi untuk memudahkan pembacaan dan diberikan penjelasan secara deskriptif.

\section{HASIL PENELITIAN DAN \\ PEMBAHASAN}

\section{Deskripsi Data}

Berdasarkan hasil penelitian diperoleh gambaran dekriptif sebagai berikut: 
Rata-rata Kecenderungan Data Variabel Penelitian

\begin{tabular}{lcc}
\hline \multicolumn{1}{c}{ Variabel } & $\begin{array}{c}\text { Skor Rata-rata } \\
\text { Kecenderungan }\end{array}$ & Kategori \\
\hline Supervisi kepala sekolah $\left(\mathrm{X}_{1}\right)$ & 4,06 & Tinggi \\
Iklim Kerja $\left(\mathrm{X}_{2}\right)$ & 4,06 & Tinggi \\
Motivasi Kerja $(\mathrm{Y})$ & 4,12 & Tinggi \\
Rata-rata kecenderungan total & $\mathbf{4 , 0 8}$ & Tinggi \\
\hline
\end{tabular}

Gambaran yang menunjukkan kerja guru ini tampak nilai rata-rata pada tingginya aktivitas supervisi yang dilakukan semua dimensi-dimensi kinerja guru. kepala sekolah dan iklim kerja dan motivasi

Tabel 2 Regresi Antara Variabel $X_{1}$ dengan Y

Coefficients $^{\mathrm{a}}$

\begin{tabular}{|c|c|c|c|c|c|}
\hline \multirow[t]{2}{*}{ Model } & \multicolumn{2}{|c|}{ Unstandardized Coefficients } & Standardized & \multirow[t]{2}{*}{$\mathrm{t}$} & \multirow[t]{2}{*}{ Sig. } \\
\hline & $\mathrm{B}$ & Std. Error & Beta & & \\
\hline \multirow{2}{*}{$\begin{array}{ll}1 & \text { (Constant) } \\
& \text { SUPERVISI } \\
\end{array}$} & 45,543 & 20,976 & & 2,171 &, 004 \\
\hline & ,548 & , 146 & ,427 & 3,743 & ,000 \\
\hline
\end{tabular}

a. Dependent Variable: MOTIVASI

Berdasarkan tabel diatas persamaan regresi $\mathrm{Y}$ atas $\mathrm{X}_{1}$, adalah $\hat{\mathrm{Y}}=45,543+0.548$ $\mathrm{X}_{1}$. Dengan persamaan regresi tersebut dapat diinterprestasikan bahwa jika variabel supervisi akademik kepala sekolah $\left(\mathrm{X}_{1}\right)$ dengan motivasi kerja guru (Y) diukur dengan instrumen yang dikembangkan dalam penelitian ini, maka setiap perubahan skor supervisi akademik kepala sekolah sebesar satu satuan dapat diestimasikan skor motivasi kerja guru akan berubah sebesar 0.548 satuan pada arah yang sama.

Kriteria pengujian persamaan regresi adalah tolak $\mathrm{H}_{0}$ jika probabilitas lebih kecil dari alpha $=0.05$. Berdasarkan tabel di atas nilai probabilitas sebagaimana ditunjukkan pada kolom Sig /Significance adalah 0.004 sehingga nilai probabilitas jauh lebih kecil dari 0.05. Dapat disimpulkan koefisien regresi signifikan, atau supervisi kepala sekolah secara signifikan terhadap motivasi kerja guru.

Hasil perhitungan korelasi variabel Supervisi kepala sekolah $\left(\mathrm{X}_{1}\right)$ terhadap variabel motivasi kerja guru (Y) tampak pada tabel sebagai berikut: 
Tabel 3 Nilai Korelasi Antara $X_{1}$ dengan $Y$

\begin{tabular}{|rl|r|r|}
\multicolumn{2}{c|}{ Correlations } \\
\hline \multirow{2}{*}{ SUPERVISI } & Pearson Correlation & \multicolumn{1}{|c|}{ SUPERVISI } & \multicolumn{1}{c|}{ MOTIVASI } \\
& Sig. (2-tailed) & 1 &, $416^{* *}$ \\
& $\mathrm{~N}$ & &, 001 \\
& Pearson Correlation & 65 & 65 \\
MOTIVASI & Sig. (2-tailed) &, $016^{* *}$ & 1 \\
& $\mathrm{~N}$ & 601 & \\
\hline
\end{tabular}

**. Correlation is significant at the 0.01 level (2-tailed).

Berdasarkan hasil perhitungan $\mathrm{H}_{\mathrm{a}}$ diterima, yang artinya signifikan. diperoleh untuk $\mathrm{X}_{1}$ dengan $\mathrm{Y}$ sebesar 0,001 Terbukti bahwa supervisi akademik kepala berarti terdapat hubungan yang cukup kuat sekolah mempunyai hubungan yang antara supervisi akademik kepala sekolah signifikan terhadap motivasi kerja guru. dengan motivasi Uji signifikasi untuk $\mathrm{X}_{1}$ Hasil perhitungan dengan bantuan dengan Y diperoleh variabel supervisi SPSS 20. Nilai koefisien determinasi akademik kepala sekolah $\left(\mathrm{X}_{1}\right)$ mempunyai variabel supervisi akademik $\left(\mathrm{X}_{1}\right)$ terhadap nilai signifikan 0.001, yang lebih kecil dari motivasi kerja guru (Y). tampak pada tabel nilai probabilitas 0.05 , maka $\mathrm{H}_{\mathrm{o}}$ ditolak dan sebagai berikut:

\section{Tabel 4 Nilai Koefisien Determinasi $X_{1}$ Terhadap Y}

\begin{tabular}{|c|c|c|c|c|c|c|c|c|c|}
\hline \multicolumn{10}{|c|}{ Model Summary ${ }^{b}$} \\
\hline \multirow{2}{*}{$\begin{array}{l}\text { Mo } \\
\text { del }\end{array}$} & \multirow[t]{2}{*}{$\mathrm{R}$} & \multirow{2}{*}{$\begin{array}{c}\mathrm{R} \\
\text { Square }\end{array}$} & \multirow{2}{*}{$\begin{array}{l}\text { Adjusted } \\
\text { R Square }\end{array}$} & \multirow{2}{*}{$\begin{array}{l}\text { Std. Error of } \\
\text { the Estimate }\end{array}$} & \multicolumn{5}{|c|}{ Change Statistics } \\
\hline & & & & & $\begin{array}{l}\text { R Square } \\
\text { Change }\end{array}$ & F Change & df1 & $\mathrm{df} 2$ & $\begin{array}{l}\text { Sig. F } \\
\text { Change }\end{array}$ \\
\hline 1 &, $416^{\mathrm{a}}$ & , 173 &, 160 & 9,80376 & , 173 & 13,148 & 1 & 63 &, 001 \\
\hline
\end{tabular}

Berdasarkan tabel di atas dapat variabel supervisi kepala sekolah sebesar diketahui besarnya koefisien determinasi 17,3\%, sedangkan sisanya dipengaruhi oleh variabel supervisi kepala sekolah $\left(\mathrm{X}_{1}\right)$ faktor lain. terhadap variabel motivasi kerja guru (Y) adalah sebesar 0,173 atau $17,3 \%$. Artinya dengan $\mathbf{Y}$

\section{Analisis korelasi antara variabel $\mathbf{X}_{2}$}

Tabel 5

Persamaan Regresi Variabel $X_{2}$ dengan $Y$

Coefficients $^{\mathrm{a}}$

\begin{tabular}{|l|l|l|l|l|}
\hline Model & Unstandardized Coefficients & $\begin{array}{l}\text { Standardized } \\
\text { Coefficients }\end{array}$ & $\mathrm{t}$ & Sig. \\
\hline
\end{tabular}




\begin{tabular}{|c|c|c|c|c|c|}
\hline & B & Std. Error & Beta & & \\
\hline (Constant) & 35,561 & 17,396 & & 2,044 &, 045 \\
IKLIMKERJA &, 627 &, 153 &, 459 & 4,096 &, 000 \\
\hline
\end{tabular}

a. Dependent Variable: MOTIVASI

Berdasarkan tabel diatas persamaan regresi $\mathrm{Y}$ atas $\mathrm{X}_{1}$, adalah $\hat{\mathrm{Y}}=35,561+0.627$ $\mathrm{X}_{1}$. Dengan persamaan regresi tersebut dapat diinterprestasikan bahwa jika variabel iklim kerja $\left(\mathrm{X}_{2}\right)$ dengan motivasi kerja guru $(\mathrm{Y})$ diukur dengan instrumen yang dikembangkan dalam penelitian ini, maka setiap perubahan skor kompensasi sebesar satu satuan dapat diestimasikan skor kinerja guru akan berubah sebesar 0.627 satuan pada arah yang sama.

Makna persamaan regresi didasarkan pada hasil perhitungan dengan menggunakan bantuan SPSS 20. Yaitu seperti pada tabel di atas yaitu kriteria pengujian persamaan regresi adalah tolak $\mathrm{H}_{0}$ jika probabilitas lebih kecil dari alpha = 0.05. Berdasarkan tabel di atas nilai probabilitas sebagaimana ditunjukkan pada kolom Sig /Significance adalah 0.000 sehingga nilai probabilitas jauh lebih kecil dari 0.05. Dapat disimpulkan koefisien regresi signifikan, atau kompensasi berpengaruh secara signifikan terhadap kinerja guru.

Hasil perhitungan dengan bantuan SPSS 20. Nilai korelasi variable iklim kerja $\left(\mathrm{X}_{2}\right)$ terhadap variabel motivasi kerja guru (Y) tampak pada tabel sebagai berikut:

Tabel 6

Nilai Korelasi antara Variabel $X_{2}$ dan $Y$

Correlations

\begin{tabular}{|ll|r|r|}
\hline & & IKLIMKERJA & \multicolumn{1}{c|}{ MOTIVASI } \\
\hline \multirow{4}{*}{ IKLIMKERJA } & Pearson Correlation & 1 &, $459^{* *}$ \\
& Sig. (2-tailed) & &, 000 \\
& $\mathrm{~N}$ & 65 & 65 \\
& Pearson Correlation &, $459^{* *}$ & 1 \\
\multirow{2}{*}{ MOTIVASI } & Sig. (2-tailed) &, 000 & 65 \\
& $\mathrm{~N}$ & 65 & \\
\multirow{2}{*}{ **. Correlation is significant at the 0.01 level (2-tailed). }
\end{tabular}

Berdasarkan hasil perhitungan diperoleh variabel kompensasi $\left(\mathrm{X}_{2}\right)$ dengan SPSS 20 nilai korelasi yang mempunyai nilai signifikan 0.000 , yang diperoleh untuk $\mathrm{X}_{2}$ dengan $\mathrm{Y}$ sebesar 0,459 lebih kecil dari nilai probabilitas 0.05 , maka berarti terdapat hubungan yang cukup kuat $\mathrm{H}_{\mathrm{o}}$ ditolak dan $\mathrm{H}_{\mathrm{a}}$ diterima, yang artinya antara iklim kerja dengan motivasi kerja signifikan. Terbukti bahwa kompensasi guru. Uji signifikasi untuk $\mathrm{X}_{2}$ dengan $\mathrm{Y}$ 
mempunyai hubungan yang signifikan variabel iklim kerja $\left(\mathrm{X}_{2}\right)$ terhadap motivasi terhadap kinerja guru. kerja guru (Y). tampak pada tabel sebagai

Nilai Koefisien Determinasi berikut:

Hasil perhitungan dengan bantuan

SPSS 20. Nilai koefisien determinasi

Tabel 7

Nilai Koefisien Determinasi Antara $X_{2}$ dengan Y

Model Summary ${ }^{b}$

\begin{tabular}{|l|r|r|r|r|r|r|r|r|r|}
\hline Model & $\mathrm{R}$ & $\mathrm{R}$ & Adjusted R & Std. Error of & \multicolumn{5}{|c|}{ Change Statistics } \\
\cline { 6 - 10 } & & $\begin{array}{c}\text { Squar } \\
\text { Square }\end{array}$ & the Estimate & $\begin{array}{c}\text { R Square } \\
\text { Change }\end{array}$ & F Change & df1 & df2 & $\begin{array}{c}\text { Sig. F } \\
\text { Change }\end{array}$ \\
\hline 1 &, $459^{\mathrm{a}}$ &, 210 &, 198 & 9,57824 &, 210 & 16,776 & 1 & 63 &, 000 \\
\hline
\end{tabular}

a. Predictors: (Constant), IKLIMKERJA

b. Dependent variable: MOTIVASI

Berdasarkan tabel di atas dapat dipengaruhi oleh variabel iklim kerja sebesar diketahui besarnya koefisien determinasi 21\%, sedangkan sisanya dipengaruhi oleh variabel iklim kerja $\left(\mathrm{X}_{2}\right)$ terhadap variabel faktor lain.

motivasi kerja guru (Y) adalah sebesar 0,210 atau $21 \%$. Artinya motivasi kerja guru

3) Analisis korelasi antara variabel $X_{1}$ dan $\mathrm{X}_{2}$ dengan $\mathrm{Y}$

Tabel 8 Persamaan Regresi $Y$ atas $X_{1}$ dan $X_{2}$

Coefficients

\begin{tabular}{|l|r|r|r|r|r|}
\hline \multirow{2}{*}{ Model } & \multicolumn{2}{|c|}{ Unstandardized Coefficients } & \multicolumn{1}{|c|}{$\begin{array}{c}\text { Standardized } \\
\text { Coefficients }\end{array}$} & \multirow{2}{*}{ Sig. } \\
\cline { 2 - 4 } & \multicolumn{1}{|c|}{$\mathrm{B}$} & Std. Error & \multicolumn{1}{|c|}{ Beta } & & \\
\hline (Constant) & $-13,171$ & 22,419 & &,- 587 &, 559 \\
IKLIMKERJA &, 535 &, 146 &, 391 & 3,663 &, 001 \\
SUPERVISI &, 414 &, 131 &, 338 & 3,160 &, 002 \\
\hline
\end{tabular}

a. Dependent Variable: MOTIVASI

Berdasarkan data pada tabel di atas, persamaan regresi $\mathrm{Y}$ atas $\mathrm{X}_{1}$, dan $\mathrm{X}_{2}$ adalah $: \hat{Y}=-13,171+0,414 X_{1}+0,535 X_{2}$ Dengan persamaan regresi tersebut dapat diinterprestasikan bahwa jika variabel supervisi kepala sekolah $\left(\mathrm{X}_{1}\right)$ dan variabel iklim kerja $\left(\mathrm{X}_{2}\right)$ dengan motivasi kerja guru (Y) diukur dengan instrumen yang dikembangkan dalam penelitian ini, maka setiap perubahan skor supervisi akademik kepala sekolah dan iklim kerja sebesar satu satuan dapat diestimasikan skor motivasi kerja guru akan berubah sebesar 0,414 satuan $X_{1}$ dan 0,535 satuan $X_{2}$ pada arah yang sama.

Makna persamaan regresi didasarkan pada hasil perhitungan dengan menggunakan bantuan SPSS 20 adalah 
kriteria pengujian persamaan regresi adalah sekolah dan iklim kerja berpengaruh secara tolak $\mathrm{H}_{0}$ jika probabilitas lebih kecil dari signifikan terhadap motivasi kerja guru.

alpha $=0.05$. Berdasarkan tabel di atas nilai

Hasil perhitungan dengan bantuan probabilitas sebagaimana ditunjukkan pada SPSS 20. Nilai korelasi variabel supervisi kolom Sig /Significance adalah -0,587 kepala sekolah $\left(\mathrm{X}_{1}\right)$ dan iklim kerja $\left(\mathrm{X}_{2}\right)$ sehingga nilai probabilitas jauh lebih kecil dari 0.05. Dapat disimpulkan koefisien terhadap variabel motivasi kerja guru (Y) regresi signifikan, atau supervisi kepala

\section{Tabel 9}

Nilai Koefisien Korelasi $X_{1}$ dan $X_{2}$ Terhadap Y

Correlations

\begin{tabular}{|ll|r|r|r|}
\hline & & SUPERVISI & IKLIMKERJA & MOTIVASI \\
\hline \multirow{5}{*}{ SUPERVISI } & Pearson Correlation & 1 &, 199 &, $416^{* * *}$ \\
& Sig. (2-tailed) & &, 113 &, 001 \\
& $\mathrm{~N}$ & 65 & 65 & 65 \\
& Pearson Correlation &, 199 & 1 &, $459^{* *}$ \\
\multirow{5}{*}{ IKLIMKERJA } & Sig. (2-tailed) &, 113 & &, 000 \\
& $\mathrm{~N}$ & 65 & 65 & 65 \\
& Pearson Correlation &, $416^{* *}$ &, $459^{* *}$ & 1 \\
MOTIVASI & Sig. (2-tailed) &, 001 &, 000 & \\
& $\mathrm{~N}$ & 65 & 65 & 65 \\
\hline
\end{tabular}

Besarnya korelasi antara variabel dan iklim kerja terhadap motivasi kerja guru supervisi kepala sekolah dan iklim kerja tergolong cukup kuat.

dengan secara bersama-sama terhadap Hasil perhitungan dengan bantuan kmotivasi kerja guru yang dihitung dengan SPSS 16. Nilai koefisien determinasi koefisien korelasi adalah 0,416. Dengan variabel supervisi akademik kepala sekolah demikian dapat diinterprestasikan bahwa $\left(\mathrm{X}_{1}\right)$ dan kompensasi $\left(\mathrm{X}_{2}\right)$ terhadap kinerja hubungan antara supervisi kepala sekolah guru (Y). tampak pada tabel sebagai berikut:

Tabel 10

Koefisien Determinasi Variabel $X_{1}$ dan $X_{2}$ Terhadap $Y$ Model Summary ${ }^{b}$

\begin{tabular}{|l|r|r|r|r|}
\hline Model & \multicolumn{1}{|c|}{$\mathrm{R}$} & \multicolumn{1}{c|}{ R Square } & $\begin{array}{c}\text { Adjusted R } \\
\text { Square }\end{array}$ & $\begin{array}{l}\text { Std. Error of } \\
\text { the Estimate }\end{array}$ \\
\hline 1 &, $566^{\mathrm{a}}$ &, 320 &, 298 & 8,96039 \\
\hline
\end{tabular}

a. Predictors: (Constant), SUPERVISI, IKLIMKERJA

b. Dependent Variable: MOTIVASI 
Berdasarkan tabel di atas dapat bersama-sama antara guru dan kepala diketahui besarnya koefisien determinasi variabel supervisi kepala sekolah $\left(\mathrm{X}_{1}\right)$ dan iklim kerja $\left(\mathrm{X}_{2}\right)$ secara bersama-sama terhadap variabel motivasi kerja guru (Y) adalah sebesar 0,320 atau $32 \%$. Artinya motivasi kerja guru dipengaruhi oleh variabel supervisi kepala sekolah dan Variabel iklim kerja secara bersama-sama sebesar 32\%, sedangkan sisanya dipengaruhi oleh faktor lain.

\section{Pembahasan}

Kontribusi Supervisi Kepala Sekolah terhadap Motivasi Kerja

Setiap lembaga pendidikan memiliki perencanaan program pendidikan yang telah disusun untuk dilaksanakan secara bertanggung jawab. Kepala sekolah pada dasarnya memiliki tanggung jawab yang besar untuk mengelola, merencanakan, mengawasi dan melaksanakan program yang telah disepakati bersama. Salah satu kewajiban kepala sekolah adalah melakukan supervisi akademik bagi guru-guru yang berada dibawah tanggung jawabnya.

Supervisi yang dilakukan kepala sekolah bukan hanya sekedar kontrol atau melihat apakah kegiatan yang ada telah berlangsung sesuai dengan program yang telah dicanangkan. Tetapi lebih dari itu melalui pelaksanaan supevisi akademik juga diharapkan dapat membina hubungan yang baik dengan guru-guru sehingga secara sekolah menyusun strategi sehingga terdapat peningkatan kinerja guru.

Berdasarkan hasil perhitungan dengan SPSS 20 nilai korelasi yang diperoleh untuk $\mathrm{X}_{1}$ dengan $\mathrm{Y}$ sebesar 0,001 berarti terdapat hubungan yang cukup kuat antara supervisi kepala sekolah dengan kinerja guru Uji signifikasi untuk $\mathrm{X}_{1}$ dengan $\mathrm{Y}$ diperoleh variabel supervisi kepala sekolah $\left(\mathrm{X}_{1}\right)$ mempunyai nilai signifikan 0.000 , yang lebih kecil dari nilai probabilitas 0.05, maka $\mathrm{H}_{\mathrm{o}}$ ditolak dan $\mathrm{H}_{\mathrm{a}}$ diterima, yang artinya signifikan. Terbukti bahwa supervisi akademik kepala sekolah mempunyai hubungan yang signifikan terhadap kinerja guru. Besarnya koefisien determinasi variabel supervisi akademik kepala sekolah $\left(\mathrm{X}_{1}\right)$ terhadap variabel kinerja guru $(\mathrm{Y})$ adalah sebesar 0,001 atau 0,173 atau $17,3 \%$. Artinya motivasi kerja guru dipengaruhi oleh variabel supervisi kepala sekolah sebesar 17,3\%, sedangkan sisanya dipengaruhi oleh faktor lain.

\section{Kontribusi Iklim Kerja Terhadap}

\section{Motivasi Kerja}

Setiap organisasi akan memiliki iklim kerja yang berbeda. Keanekaragaman pekerjaan yang dirancang organisasi, atau sifat individu yang ada akan menggambarkan perbedaan tersebut. Dalam iklim kerja di sekolah, tentunya keanekaragaman pekerjaan dalam 
mengelola siswa ataupun

Diantara hal-hal yang dapat pengadministrasian, juga latar belakang memotivasi kerja guru diantaranya adalah pendidik dan tenaga kependidikan yang berbeda maka tentu akan berbeda pula keadaannya.

Telah banyak penelitian yang mempelajari kontribusi iklim kerja bagi motivasi kerja guru, menunjukan bahwa iklim kerja ini menarik untuk dipelajari bagaimana hal tersebut dapat meningkatkan motivasi kerja guru, atau dalam hal ini adalah guru SD Negeri di Kecamatan Kertasemaya Kabupaten Indramayu. Iklim kerja, telah terbukti dapat mempengaruhi kinerja seseorang. Dalam penelitian ini, nilai probabilitas sebagaimana ditunjukkan pada kolom nilai probabilitas sebagaimana ditunjukkan pada kolom Sig /Significance adalah 0.004 sehingga nilai probabilitas jauh lebih kecil dari 0.05. Dapat disimpulkan koefisien regresi signifikan, atau supervisi kepala sekolah secara signifikan terhadap motivasi kerja guru.

Berdasarkan hasil pengolahan data dapat diketahui besarnya koefisien determinasi variabel iklim kerja $\left(\mathrm{X}_{2}\right)$ terhadap variabel motivasi kerja guru (Y) adalah sebesar 0,210 atau 21\%. Artinya motivasi kerja guru dipengaruhi oleh variabel iklim kerja sebesar $21 \%$, sedangkan sisanya dipengaruhi oleh faktor Kontribusi antara Supervisi Kepala Sekolah dan Iklim Kerja terhadap Motivasi Kerja adanya pengaturan lingkungan fisik, pengaturan suasana kerja, disiplin, dorongan dan penghargaan sesuai dengan kinerjanya. Adanya supervisi akademik dari kepala sekolah juga seringkali dapat memotivasi guru agar dapat meningkatkan kinerjanya. Berdasarkan pemaparan diatas, dapat kita simpulkan bahwa guru merupakan kunci dari keberhasilan proses pendidikan. Sehingga motivasi kerja guru, dan hal-hal yang dapat mempengaruhinya, diantaranya variabel iklim kerja dan kegiatan supervisi kepala sekolah merupakan bahan kajian yang penting dalam ilmu manajemen pendidikan.

Menurut Nur Aedi (2014:16) supervisi pendidikan pada dasarnya diarahkan pada tiga kegiatan, yaitu supervisi akademis, supervisi administrasi dan supervisi lembaga.Ketiga kegiatan besar tersebut masing-masing memiliki garapan serta wilayah tersendiri. Supervisi akademik sendiri dititikberatkan pada pengamatan supervisor tentang masalah-masalah yang berhubungan dengan kegiatan akademis, diantaranya hal-hal yang langsung berada dalam lingkungan kegiatan pembelajaran pada waktu siswa sedang dalam proses mempelajari sesuatu.

Supervisi akademik kepala sekolah merupakan aspek yang menunjang 
peningkatan untuk memotivasi kerja guru.

Selain faktor supervisi, faktor iklim kerja juga memberikan pengaruh terhadap motivasi kerja guru. Besarnya korelasi antara variabel supervisi kepala sekolah dan iklim kerja dengan secara bersama-sama terhadap kmotivasi kerja guru yang dihitung dengan koefisien korelasi adalah 0,416. Dengan demikian dapat diinterprestasikan bahwa hubungan antara supervisi kepala sekolah dan iklim kerja terhadap motivasi kerja guru tergolong cukup kuat.

Berdasarkan hasil analisis data dapat diketahui besarnya korelasi antara variabel supervisi kepala sekolah $\left(\mathrm{X}_{1}\right)$ dan iklim kerja $\left(\mathrm{X}_{2}\right)$ dengan secara bersama-sama terhadap motivasi kerja guru (Y) yang dihitung KESIMPULAN

Berdasarkan analisis data dan pengujian hipotesis dapat diambil kesimpulan sebagai berikut:

1. Supervisi kepala sekolah berpengaruh secara signifikan terhadap kinerja guru SD Negeri di Kecamatan Kertasemaya Kabupaten Indramayu, besarnya koefisien determinasi variabel supervisi kepala sekolah $\left(\mathrm{X}_{1}\right)$ terhadap variabel Motivasi kerja guru (Y) adalah sebesar 0,173 atau $17,3 \%$. Artinya Kinerja guru dipengaruhi oleh variabel supervisi akademik kepala sekolah sebesar 17,3\%

2. Iklim kerja berpengaruh secara signifikan terhadap motivasi kerja guru dengan koefisien korelasi adalah 0,416. Dengan demikian dapat diinterprestasikan bahwa hubungan antara supervisi kepala sekolah dan iklim kerja terhadap motivasi kerja guru tergolong cukup kuat.

Berdasarkan penghitungan data dapat diketahui besarnya koefisien determinasi variabel supervisi kepala sekolah $\left(\mathrm{X}_{1}\right)$ dan iklim kerja $\left(\mathrm{X}_{2}\right)$ secara bersama-sama terhadap variabel motivasi kerja guru (Y) adalah sebesar 0,320 atau $32 \%$. Artinya motivasi kerja guru dipengaruhi oleh variabel supervisi kepala sekolah dan Variabel iklim kerja secara bersama-sama sebesar 32\%, sedangkan sisanya dipengaruhi oleh faktor.

SD Negeri di Kecamatan Kertasemaya Kabupaten Indramayu. Besarnya koefisien determinasi variabel iklim kerja $\left(\mathrm{X}_{2}\right)$ terhadap variabel motivasi kerja guru (Y) adalah sebesar 0,210 atau $21 \%$. Artinya kinerja guru dipengaruhi oleh variabel kompensasi sebesar $21 \%$

3. Supervisi kepala sekolah dan iklim kerja secara bersama-sama berpengaruh secara signifikan terhadap motivasi kerja guru SD Negeri di Kecamatan Kertasemaya Kabupaten Indramayu. Besarnya koefisien determinasi variabel supervisi kepala sekolah (X1) dan iklim kerja $\left(\mathrm{X}_{2}\right)$ secara bersama-sama 
terhadap variabel motivasi kerja guru (Y) adalah sebesar 0,320 atau $32 \%$. Artinya motivasi kerja guru dipengaruhi oleh variabel supervisi kepala sekolah dan variabel iklim kerja secara bersamasama sebesar $32 \%$, sedangkan sisanya dipengaruhi oleh faktor lain.

\section{A. Saran}

1. Peningkatan peran supervisi kepala sekolah terhadap guru-guru harus mendapatkan perhatian yang baik. Intensitas dan bentuk supervisi sebaiknya ditetapkan secara bersamasama dan dilaksanakan secara konsisten, agar terdapat evaluasi yang baik bagi guru maupun bagi kepala sekolah

2. Iklim kerja yang baik harus mendapat perhatian yang lebih dari berbagai pihak agar motivasi kerja terbangun dengan lebih baik untuk peningkatan mutu pendidikan.

3. Upaya peningkatan motivasi kerja guru dapat dilakukan melalui peningkatan pemberdayaan kelompok guru (KKG), pembinaan dan pelatihan yang dilakukan secara intensif dan berkesinambungan.

\section{DAFTAR PUSTAKA}

Aedi, N. (2014). Pengawasan Pendidikan. Jakarta: Rajagrapindo Perkasa.
Akdon \& Hadi, S. (2005). Aplikasi Statistik dan Metode Penelitian untuk Administrasi dan Manajemen. Bandung: Dewa Ruci.

Faizin. (2018). Pengaruh Kompetensi Profesional Guru, Motivasi Kerja Dan Konsep Diri Terhadap Kinerja Guru Di Madrasah Aliyah Negeri Kabupaten Kampar. Jurnal PAJAR (Pendidikan dan Pengajaran), Vol 2, No 4, Juli 2018.

Harjali. (2016). Strategi Guru dalam Membangun Lingkungan Belajar yang Kondusif: Studi Fenomenologi pada Kelas-kelas Sekolah Menengah Pertama di Ponorogo. Jurnal Pendidikan Dan Pembelajaran, Vol 23, No 1, April 2016.

Jumadiah N, dkk. (2016). Implementasi Supervisi Akademik Kepala Mis Batusangkar. JMKSP (Jurnal Manajemen, Kepemimpinan, dan Supervisi Pendidikan). Vol 1, No. 2, Juli-Desember 2016.

Kenedi. (2017). Pengembangan Kreativitas Siswa Dalam Proses Pembelajaran Di Kelas Ii Smp Negeri 3 Rokan Iv Koto, Suara Guru : Jurnal Ilmu Pendidikan Sosial, sains, dan Humaniora, Vol. 3 No. 2, Hal 329 - 347, Juni 2017

Manizar, E. (2015). Peran Guru Sebagai Motivator Dalam Belajar, Tadrib, vol 1, no 2, desember 2015.

Supriyo. (2015). Motivasi Kerja Guru SMP Negeri di Kota Semarang. Cakrawala Pendidikan, Vol 10, No 1, Februari 2015. 